\title{
Evidence-based management of traumatic thoracolumbar burst fractures: a systematic review of nonoperative management
}

\author{
Joshua Bakhsheshian, M.S., Nader S. Dahdaleh, M.D., Shayan Fakurnejad, B.S., \\ Justin K. Scheer, B.S., and Zachary A. Smith, M.D. \\ Department of Neurological Surgery, Northwestern University, Feinberg School of Medicine, Chicago, \\ Illinois
}

Object. The overall evidence for nonoperative management of patients with traumatic thoracolumbar burst fractures is unknown. There is no agreement on the optimal method of conservative treatment. Recent randomized controlled trials that have compared nonoperative to operative treatment of thoracolumbar burst fractures without neurological deficits yielded conflicting results. By assessing the level of evidence on conservative management through validated methodologies, clinicians can assess the availability of critically appraised literature. The purpose of this study was to examine the level of evidence for the use of conservative management in traumatic thoracolumbar burst fractures.

Methods. A comprehensive search of the English literature over the past 20 years was conducted using PubMed (MEDLINE). The inclusion criteria consisted of burst fractures resulting from a traumatic mechanism, and fractures of the thoracic or lumbar spine. The exclusion criteria consisted of osteoporotic burst fractures, pathological burst fractures, and fractures located in the cervical spine. Of the studies meeting the inclusion/exclusion criteria, any study in which nonoperative treatment was used was included in this review.

Results. One thousand ninety-eight abstracts were reviewed and 447 papers met inclusion/exclusion criteria, of which 45 were included in this review. In total, there were 2 Level-I, 7 Level-II, 9 Level-III, 25 Level-IV, and 2 Level$\mathrm{V}$ studies. Of the 45 studies, 16 investigated conservative management techniques, 20 studies compared operative to nonoperative treatments, and 9 papers investigated the prognosis of conservative management.

Conclusions. There are 9 high-level studies (Levels I-II) that have investigated the conservative management of traumatic thoracolumbar burst fractures. In neurologically intact patients, there is no superior conservative management technique over another as supported by a high level of evidence. The conservative technique can be based on patient and surgeon preference, comfort, and access to resources. A high level of evidence demonstrated similar functional outcomes with conservative management when compared with open surgical operative management in patients who were neurologically intact. The presence of a neurological deficit is not an absolute contraindication for conservative treatment as supported by a high level of evidence. However, the majority of the literature excluded patients with neurological deficits. More evidence is needed to further classify the appropriate burst fractures for conservative management to decrease variables that may impact the prognosis.

(http://thejns.org/doi/abs/10.3171/2014.4.FOCUS14159)

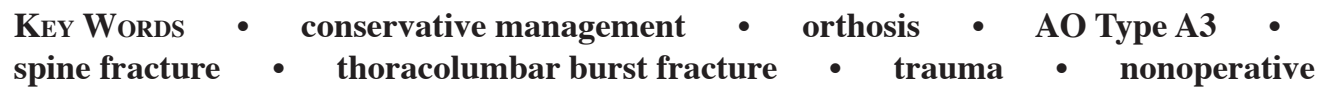

$\mathrm{T}$ ThORACIC and lumbar spinal fractures are common traumatic injuries that can include compression, burst, flexion-distraction, and fracture-dislocation injuries..$^{20,32,41}$ The majority of thoracic and lumbar spinal fractures occur at or nearby the thoracolumbar junction, a transitional zone of the spine where the kyphotic thoracic spine meets the lordotic lumbar spine. ${ }^{32,41}$ Burst fractures are primarily a result of axial compressive forces and ac-

Abbreviations used in this paper: ODI = Oswestry Disability Index; RCT $=$ randomized controlled trial; RMDQ = Roland-Morris Disability Questionnaire; SF-36 = 36-Item Short-Form Health Survey; $\mathrm{TLSO}=$ thoracolumbar orthosis; $\mathrm{VAS}=$ visual analog scale. count for more than $60 \%$ of thoracolumbar fractures..$^{20,23,41}$ Despite the increasing literature on the management of thoracolumbar burst fractures, the optimal treatment strategy remains unclear. The presence of neurological deficits is an indication for operative management, but the indications for conservative management continue to be controversial. $6,21,33,41$

The current goal in the treatment of traumatic thoracolumbar burst fractures is to stabilize the spine to prevent short- and long-term deformity and neurological decline while improving the clinical outcome of the patient. Spine fractures are unstable due to the failure of the middle column, posterior ligamentous complex inju- 


\section{J. Bakhsheshian et al.}

ry, or the presence of neurological deficits. ${ }^{20,41,60,62}$ Using these factors to guide operative or nonoperative treatment methods has demonstrated the greatest discordance with burst fractures. ${ }^{33}$ Recent studies comparing operative to nonoperative treatment in burst fractures without a neurological deficit have found no differences in the functional outcome between these treatment modalities, and moreover, operative management has been correlated with increased costs and complications. ${ }^{1,24,58,65}$ While operative management was reported to be more effective in preventing the progression of sagittal deformity in stable burst fractures, it has been shown to have no correlation with the functional outcomes reported by patients..$^{55}$

Nonoperative management is used to stabilize the spine by limiting motion and can consist of recumbent bed rest, closed reduction, orthosis, and body cast with or without ambulation., $4,5,13,15,36,46,54,57$ Two decades ago, results from 2 independent studies contradicted the contention that patients with burst fractures will demonstrate deterioration in neurological function if treated conservatively. ${ }^{13,46}$ These studies showed that neurological deterioration is rare, with most patients reporting minimal to no pain and satisfactory work status. Many subsequent studies demonstrated similar findings with a variety of conservative techniques, ${ }^{2,4,10,15,54,57}$ but the supporting literature is unclear. For example, postural reduction and stabilization with conservative management has been reported to decompress the spinal canal, while others have reported no additional therapeutic benefit. 4,16,36,42,48,54

To the authors' best knowledge, there has not been a systematic review focusing on the level of evidence for the use of conservative management in the treatment of traumatic thoracolumbar burst fractures. Current systematic reviews compared operative and nonoperative treatment in neurologically intact patients. ${ }^{1,24,58,65}$ These studies were limited by mainly including randomized controlled trials (RCTs) or using nonstandardized criteria to assess the level of evidence. By assessing the level of evidence in conservative management through validated methodologies, clinicians can assess the availability of critically appraised literature. ${ }^{29-31,40}$ In the following report, we evaluated the level of evidence regarding the nonoperative management of traumatic thoracolumbar burst fractures, specifically in regards to the various nonoperative techniques, operative versus nonoperative management, and the prognosis of patients treated conservatively.

\section{Methods}

A systematic review of the English literature over the last 20 years was conducted according to the Cochrane guidelines (http://handbook.cochrane.org). An electronic search of the entire PubMed database (MEDLINE) up to December 17, 2013, was performed to identify studies with various combinations of the following search terms: "spine AND burst" or "burst fracture" or "burst AND fracture" or "A3 AND fracture AND spine." The inclusion criteria consisted of burst fractures resulting from a traumatic mechanism, and fractures of the thoracic or lumbar spine. The exclusion criteria consisted of osteoporotic burst fractures, pathological burst fractures, and fractures located in the cervical spine. When inclusion or exclusion was unclear based on title and abstract, full-text articles were retrieved. Studies between January 1, 1992, and December 17, 2013, were included because the management of burst fractures has evolved significantly over the last 20 years.

Included articles were categorized based on study type and topic. The study type categories included 1) case-control studies, 2) case reports, 3) case series, 4) comparative studies, 5) RCTs, 6) narrative reviews, and 7) systematic reviews. A comparative study was defined as a study comparing two cohorts, but one that did not meet the criteria for an RCT. Similarly, a narrative review article did not meet the standard guidelines for a systematic review. Study topic categories included diagnosis, prognosis, operative versus nonoperative management, and treatment/technique. The treatment/technique category included all studies in which the focus was specifically treating burst fractures (including bracing and nonoperative methods) or the use of a given technique. Further data extracted from each article included the following: publication year, number of patients, study population and etiologies, average follow-up period, assessment or outcome measures, and study conclusions. The following study characteristics were also recorded: prospective or retrospective status, whether nonoperative treatment was used, and if all patients were neurologically intact prior to treatment. Following completion of the entire data set, the articles in which conservative management was used were selected for this review. Studies that investigated solely a pediatric population or that lacked follow-up outcome measures specific to conservative treatment were excluded. Levels of evidence were assigned to the studies according to the criteria set forth in the journal Clinical Orthopedics and Related Research, which is adapted from the Oxford Centre of Evidence Based Medicine levels of evidence. ${ }^{29-31,40}$ The level of evidence scale has 5 levels, with Level I being the highest and Level V being the lowest (Table 1). Ambiguity or any disagreements between reviewers was resolved through discussion and the addition of a third reviewer if needed.

\section{Results}

\section{Article Selection}

The results of the literature search are summarized in Fig. 1. The preliminary search criteria yielded 1098 abstracts, and 447 studies involving traumatic thoracolumbar burst fractures met the inclusion and exclusion

TABLE 1: Criteria for the levels of evidence

\begin{tabular}{cc}
\hline Level & Description \\
\hline I & $\begin{array}{c}\text { systematic review of RCTs \& individual RCT w/ narrow } \\
\text { confidence interval } \\
\text { II }\end{array}$ \\
III & systematic review of cohort studies, individual cohort \\
study, \& low quality RCT \& outcome research study \\
IV & case-control study \\
V & case series, poor quality cohort, \& case-control studies \\
\end{tabular}




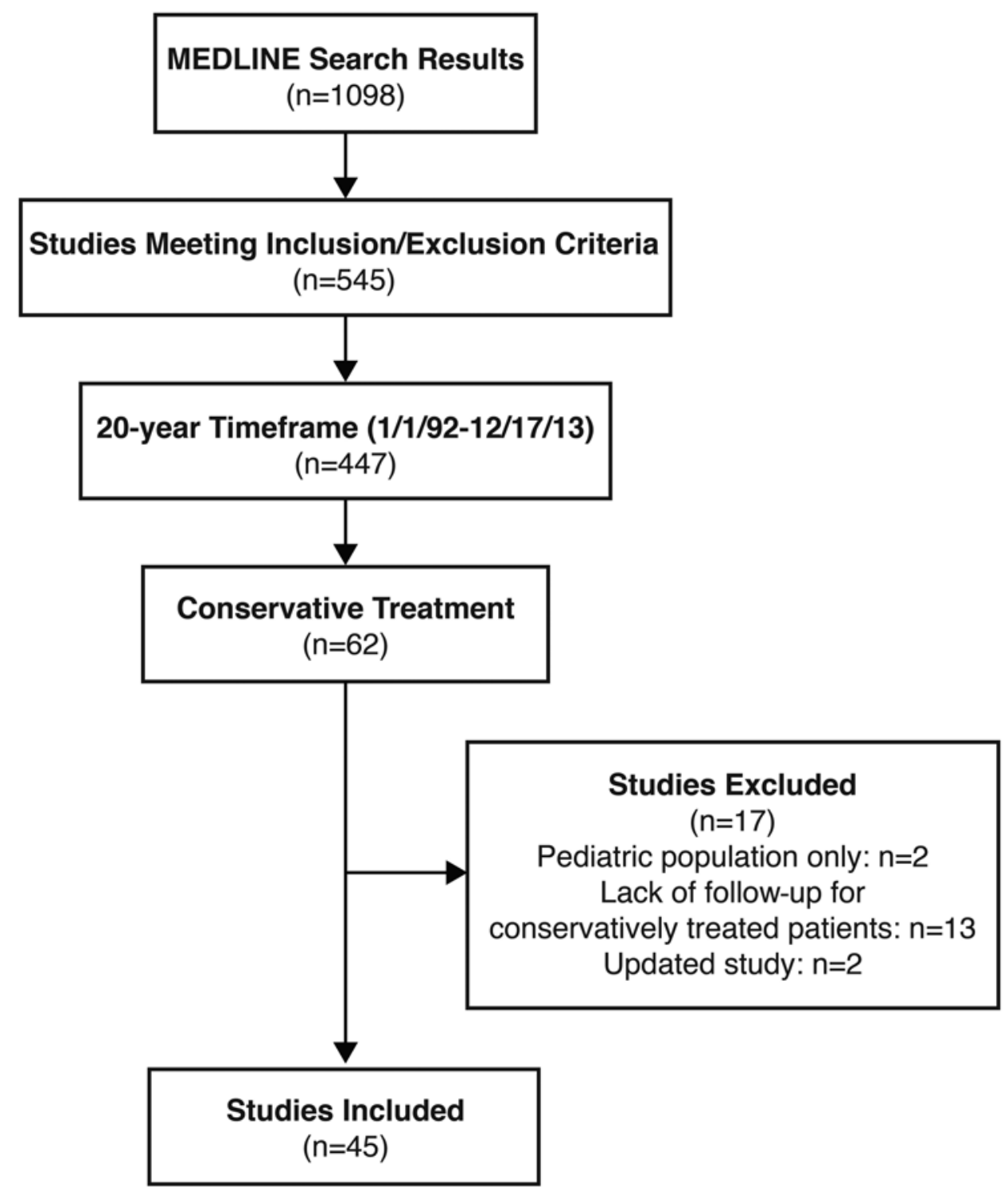

FIG. 1. Flow chart of the systematic literature search and review process.

criteria in the last 20 years. Out of 447 studies, 45 articles were identified as primarily investigating conservative management. ${ }^{1-19,22,24,25,28,34-37,43-47,49,50,52-59,61,63,64}$ There were 4 RCTs, 10 comparative studies, 25 case series, 4 systematic reviews, and 2 narrative reviews. The study types included 16 techniques, 20 operative versus nonoperative studies, and 9 prognosis studies. There were 14 prospective and 25 retrospective studies, and the remaining were reviews (not applicable). The level of evidence in hierarchical order was as follows: Level I $(\mathrm{n}=2,4 \%)$, Level II $(\mathrm{n}=7,16 \%)$, Level III $(\mathrm{n}=9,20 \%)$, Level IV $(\mathrm{n}=25$, $56 \%)$, and Level V $(\mathrm{n}=2,4 \%)$. Level I and Level II studies are summarized in Table 2. A summary of the level of evidence is found below with an emphasis on higher-level studies (Levels I and II).

\section{Conservative Treatment Techniques}

Sixteen total studies investigated conservative treatment techniques. Two of the 16 studies specifically compared different methods of conservative treatments for thoracolumbar burst fractures without neurological deficits, and were both Level-II RCTs. The most recent Level-II RCT was reported by Bailey et al. in 2013. ${ }^{9}$ They compared treatment with thoracolumbar orthosis (TLSO) to no TLSO in 96 patients with T11-L3 burst fractures. Isolated AO Type A3 fractures with a kyphotic deformity less than $35^{\circ}$ were included. Follow-up was planned for as long as 2 years for primary and secondary functional outcome measures. There was no difference in RolandMorris Disability Questionnaire (RMDQ), visual analog scale (VAS), and 36-Item Short-Form Health Survey (SF36) scores, satisfaction, and length of stay between the two treatment groups.

The second Level-II RCT was reported by Stadhouder et al. in 2009. ${ }^{56}$ They compared the treatment of a thermoplastic removable brace to a plaster of Paris cast for 12 weeks in 25 patients with T3-L5 burst fractures. Fractures were included if the anterior column compres- 
J. Bakhsheshian et al.
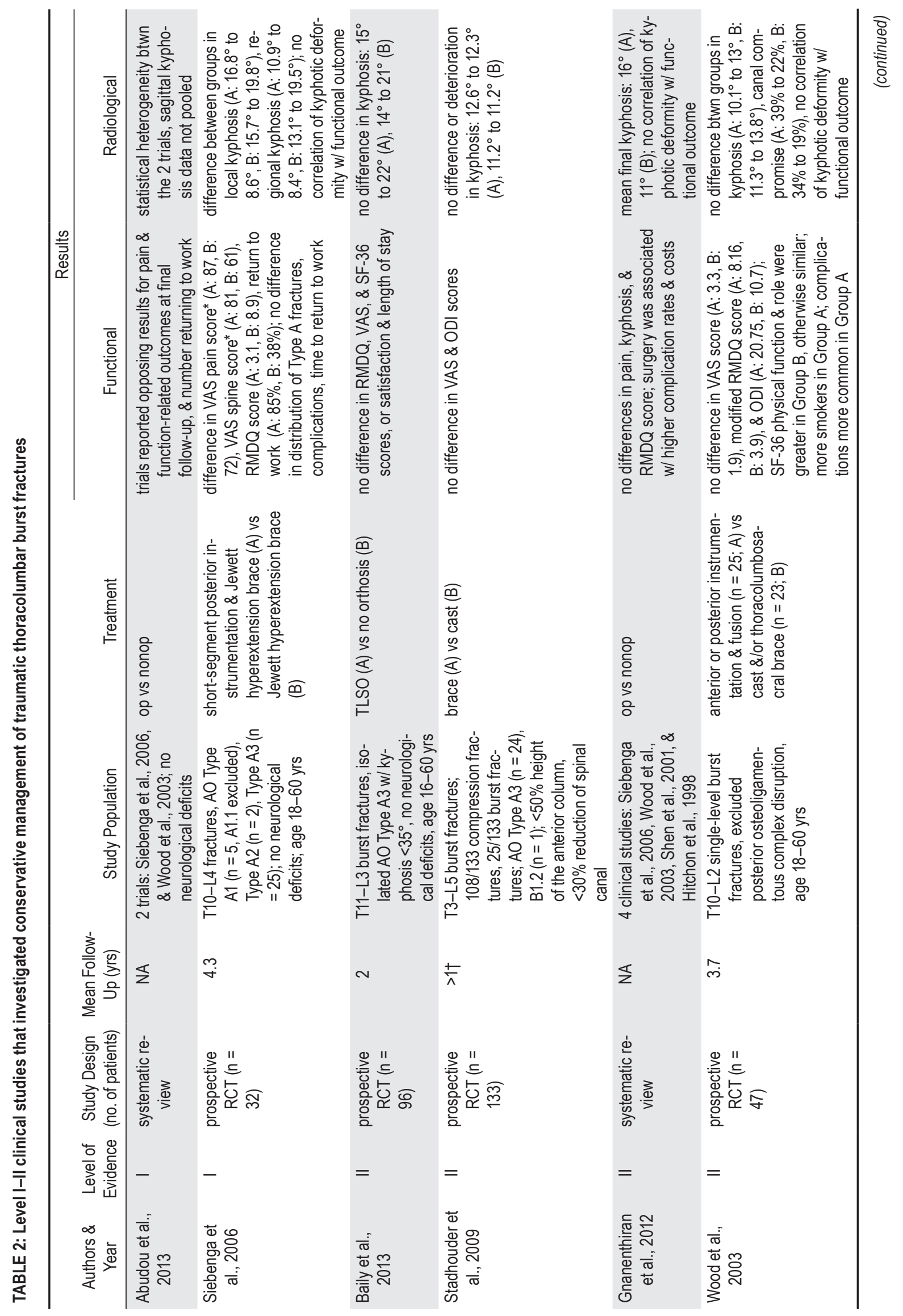

兽
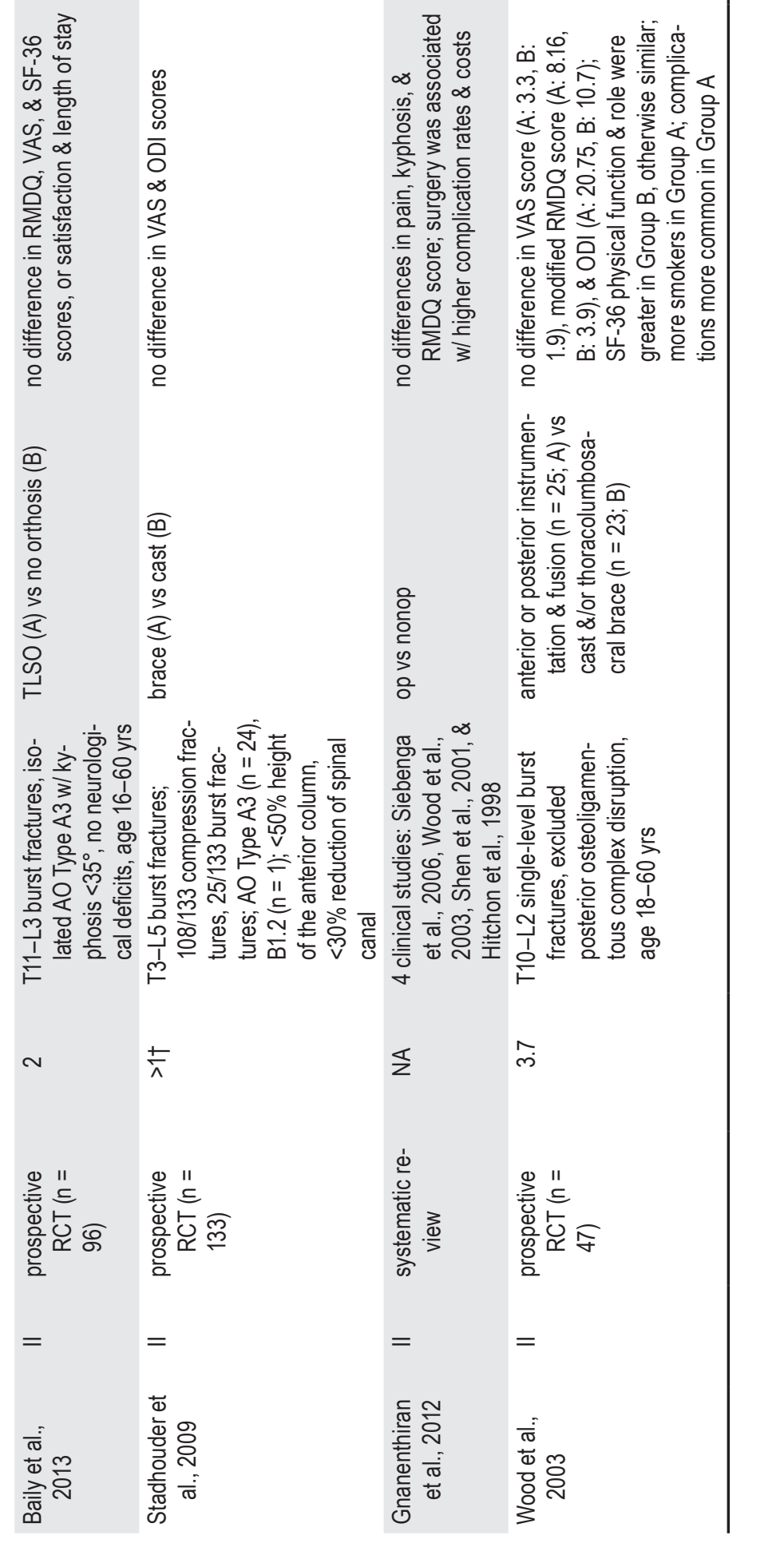
Evidence-based conservative management of burst fractures

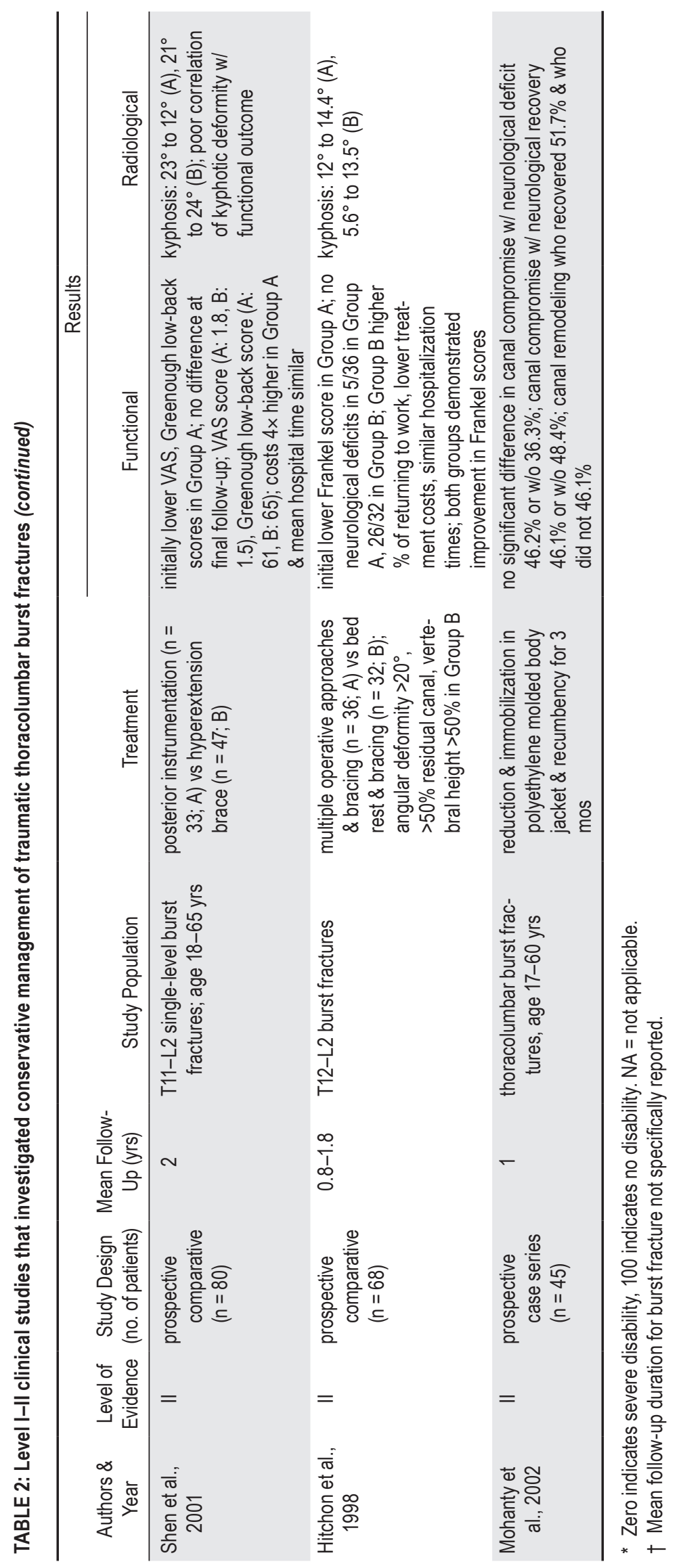




\section{J. Bakhsheshian et al.}

sion was less than $50 \%$ of the column and reduction of the spinal canal was less than $30 \%$. This study consisted of primarily AO Type A3.1-3.3 fractures and 1 AO Type B1.2 fracture. Follow-up was planned at 6 and 12 weeks and 6 and 12 months, with 1 long-term follow-up visit at least 1 year later. Radiological deformity and functional outcome were set as the primary outcome parameters. There was no difference in kyphotic changes, VAS pain score, and Oswestry Disability Index (ODI) between the treatment groups.

The remaining 14 studies employed and investigated conservative techniques that were not compared with other techniques and were rated Level IV. Of the 14 studies, 11 studies investigated conservative treatment in patients without neurological deficits. Treatment categories included either TLSO, hyperextension or Jewett brace, body cast with or without ambulation, or closed reduction..$^{2,4,10,13-15,25,46,47,54,57}$ These studies demonstrated improved outcomes from initial presentation, with most patients reporting minimal to no pain, satisfactory work level, and a kyphotic change $\leq 4^{\circ}$. The remaining 3 studies included patients with neurological deficits and demonstrated no neurological deterioration and significant reduction of canal compromise, with most patients reporting minimal back pain or disability. ${ }^{45,59,61}$

\section{Operative Versus Nonoperative Management}

Twenty papers were found to compare operative to nonoperative management. Two Level-I, 3 Level-II, 4 Level-III, 2 Level-IV, and 1 Level-V studies excluded neurological deficits, whereas 1 Level-II, 5 Level-III, 1 Level-IV, and 1 Level-V studies included neurological deficits. The most recent Cochrane review published in 2013 by Abudou et al. ${ }^{1}$ was rated as Level I. These authors included 2 RCTs (discussed below) that reported contrasting results for pain and functional outcomes at final follow-up and number of patients returning to work. The authors reported that both trials have an unclear risk of selection bias and a high risk of performance and detection bias.

The second Level-I study was an RCT by Siebenga et al. in $2006 .{ }^{55}$ The authors compared bed rest followed by mobilization with a Jewett-type orthotic device to shortsegment posterior instrumentation in 32 patients with T10-L4 burst fractures. The cohort consisted of AO Type A3 $(n=25)$, A2 $(n=2)$, and A1 (A1.1 excluded, $n=5)$ fractures. Data collection involved radiological and functional outcomes with a mean follow-up of 4.3 years. The operative group had superior VAS pain, VAS spine, and RMDQ scores, a higher percentage with return to work, and lower kyphotic deformity; complications were similar in both groups.

The second RCT by Wood et al. in 2003 was rated at Level II. ${ }^{63}$ The authors compared the application of a body cast or orthosis to anterior or posterior instrumentation with fusion in 47 patients with T10-L2 burst fractures. Burst fractures with posterior column disruptions were excluded. Data collection involved radiological and functional outcomes with a mean follow-up of 3.7 years. There were no statistical differences in return to work, kyphotic deformity, VAS scores, ODI, and RMDQ scores between the two groups. The conservative group scored higher in SF-36 subsections of physical function and role. Complications were more prevalent in the surgical group.

The second clinical study addressing operative versus nonoperative management in neurologically intact patients rated as a Level-II study was a prospective comparative trial by Shen et al. in $2001 .^{53}$ The authors prospectively compared the treatment of a customized hyperextension orthosis to posterior instrumentation by variable screw placement or Texas Scottish Rite Hospital rods in 80 patients with single-level T11-L2 burst fractures. Fracture dislocations and pedicle fractures were excluded. The study was initially randomized but 7 participants assigned to the operative group refused surgery and were reassigned to the nonoperative group. Data collection involved radiological and functional outcomes with a mean follow-up of 2 years. In the operative group, the kyphosis angle was improved initially by $17^{\circ}$, but this was gradually lost. At $1-$ and 3-month follow-up evaluations, VAS pain and Greenough Low-Back Outcome Scale scores were significantly lower in patients treated surgically. This difference was not observed at 1- and 2-year follow-up assessments.

A systematic review by Gnanenthiran et al. in 2012 that was rated Level II included the above trials (Table 2). ${ }^{24}$ The authors pooled the results in a meta-analysis and found no differences in pain, kyphosis, RMDQ score, and return to work rates between the operative and nonoperative groups. The surgical group did have better radiographic correction $\left(-3.3^{\circ}\right.$ in the nonoperative group vs $1.8^{\circ}$ in the operative group) at final follow-up, but there was a higher rate of complications and higher costs associated with surgery.

The remaining Level-II study was conducted by Hitchon et al. in 1998, in which they prospectively compared TLSO to multiple operative approaches in 68 patients with T12-L2 burst fractures. ${ }^{28}$ Patients were selected for conservative treatment if the kyphotic deformity was less than $20^{\circ}$, residual spinal canal was greater than $50 \%$, and anterior vertebral body compression was less than $50 \%$. The operative group contained significantly more patients with neurological deficits. The Frankel score classification improved by $0.5 \pm 0.7$ Frankel grades in the surgical group compared with $0.2 \pm 0.4$ Frankel grades in the conservative group. In comparison, the nonoperative group had a higher percentage of patients returning to work, lower treatment costs, and similar hospitalization durations.

The 14 remaining studies comparing operative and nonoperative management were rated Level III-V. These studies used selection criteria that resulted in more patients with neurological deficits or severe burst fractures (based on canal compromise, kyphosis, and others) in the operative management group, making direct comparisons difficult. Seven of the studies demonstrated either similar or superior functional outcomes in the nonoperative group when excluding patients with neurological deficits. ${ }^{11,12,35,37,49,50,58}$ Five studies included patients with neurological compromise and demonstrated no neurological deterioration with similar or superior functional or radiological outcomes in the nonoperative group., ${ }^{7,8,43,52,61}$ Two reviews recommended surgery for the presence of significant neurological compromise and spinal instability. ${ }^{6,17}$ 


\section{Evidence-based conservative management of burst fractures}

\section{Prognosis of Conservative Management}

Nine papers (1 Level II and 8 Level IV) investigated the prognosis of conservative management. The Level-II study was reported by Mohanty and Venkatram in 2002. ${ }^{44}$ The authors evaluated the radiological and clinical outcomes in 45 consecutive patients with thoracolumbar burst fractures treated by reduction and immobilization in a polyethylene-molded body jacket for 3 months. Data on the extent of canal compromise, initial neurological deficit, and final recovery were collected, with a mean followup duration of 1 year. The mean canal compromise had no correlation with neurological compromise, neurological recovery, or remodeling. Of the 8 Level-IV studies, 4 demonstrated no correlation between canal compromise, neurological deficit, and recovery. ${ }^{18,19,22,34}$ The remaining 4 Level-IV studies have shown that a higher Load Sharing Score $(>6)$ has a poor prognosis or that the location of fracture (thoracolumbar or lower lumbar) can impact the prognosis. , $^{3,16,36}$

\section{Discussion}

Nonoperative management offers many benefits, including decreased costs and complications with improved functional outcomes. ${ }^{1,24,53,63}$ The literature has investigated conservative management with diverse groups of patients, fracture patterns, treatment modalities, and outcome measures. Therefore, most published studies are excluded from recent high-level systematic reviews.,24 To the best of the authors' knowledge, the level of evidence for the use of conservative management in patients with traumatic thoracolumbar burst fractures has not been previously reported. In the current study, $20 \%$ of the studies published in the last 20 years meeting the inclusion/exclusion criteria demonstrate a high level of evidence (Level I or II).

Many conservative techniques stabilize the spine by limiting motion. Multiple techniques were investigated by low-level studies, whereas only 2 Level-II studies were found that compared techniques. ${ }^{4,5,13,15,36,46,54,57}$ The LevelII studies were both RCTs and found no difference between the conservative techniques employed when treating AO Type A3 thoracolumbar burst fractures. Stadhouder et al. demonstrated no difference in the use of a brace or a cast ${ }^{56}$ the body cast can restrict movements in all directions, while a brace maintains more flexibility in all directions. Bailey et al. ${ }^{9}$ demonstrated no difference in the use of a custom brace or no brace. The results question the need for a supportive orthotic device in isolated $\mathrm{AO}$ Type A3 fractures (subtypes were not specified). While the authors reported an improved functional outcome for most of the patients in the cohort, 6 patients required surgical stabilization. This may be the result of the study authors' relying on radiographic findings of fracture morphology because it has been shown that the inclusion of $\mathrm{CT}$ and MRI helps the identification of posterior column disruptions. ${ }^{38,39,51}$ This phenomenon was observed in another study in which AO Type B fractures were found intraoperatively that were originally diagnosed as AO Type A fractures preoperatively. ${ }^{55}$

The Level-I studies selected in this review that compared operative and nonoperative management without neurological deficits mainly reported no differences in the functional outcomes. However, the Level-I study by Siebenga et al. ${ }^{55}$ reported superior outcomes in the operative group. These authors did not use MRI with all their patients and found 2 AO Type B1.1 fractures intraoperatively, showing evidence of posterior ligamentous complex disruption. The unrecognized Type B fractures in the nonoperative group are unknown. Furthermore, Siebenga et al. analyzed fewer fractures at the thoracolumbar junction than the other studies, and included L-3 (2/17) and L-4 (1/17) fractures in the operative group as opposed to 1 L-3 fracture (1/15) in the nonoperative group. There is low evidence that lumbar burst fractures may have a different prognosis, and this is discussed further below. $7,10,11,14,35,43,52$ The other clinical studies reported no differences in the functional outcomes between management and were rated Level II. ${ }^{53,63}$ Wood et al. ${ }^{63}$ compared more than one nonoperative and operative technique. Furthermore, Wood et al. and Shen et al. ${ }^{53}$ investigated isolated burst fractures as opposed to Siebenga et al. While the study of Wood et al. excluded posterior ligamental disruption, the Shen et al. study did not rely on radiographic parameters, and neither used MRI. Shen et al. reported a load share score less than 6, in contrast to the mean load share score greater than 6 reported by Siebenga et al. There is low evidence that a higher load share score may correlate with a lower functional outcome in patients treated conservatively. ${ }^{5,16,36}$ Two high-level systematic reviews reported a high risk of performance and detection bias in the above studies without a recommendation for either operative or nonoperative management. ${ }^{1,24,58}$ All authors reported that costs associated with operative management are approximately 4 times greater than conservative management. ${ }^{28,53,55,63}$ These studies used surgical procedures not currently in use, and there is no literature on comparing conservative management to minimally invasive surgical approaches.

In this systematic review, 18 papers $(40 \%)$ included patients with an initial neurological deficit. Other systematic reviews limited their inclusion criteria to burst fractures without a neurological deficit. ${ }^{1,24,50,58}$ The presence of a neurological deficit may not be an absolute contraindication for conservative treatment of thoracolumbar burst fractures. ${ }^{8,16,35,45}$ Hitchon et al. have shown that nonoperative treatment can achieve similar neurological recovery to surgical management in a Level-II study. ${ }^{28}$ Numerous low-level studies have also demonstrated that conservative treatment rarely leads to neurological deterioration. ${ }^{16,26,45,59,61}$ The evidence that surgical intervention is needed to decompress the spinal canal or remove retropulsed bone to improve neurological status is also questionable. Mohanty and Venkatram demonstrated in a Level-II study that there was no correlation between the initial neurological deficit and subsequent recovery with the extent of spinal canal compromise in thoracolumbar burst fractures treated conservatively. ${ }^{44}$ There are no high-level RCT studies comparing conservative treatment of burst fractures with neurological deficits. Given that surgery is commonly used in burst fractures with neurological deficits, it is understandable why this has not been further investigated.

As stated above, lower lumbar burst fractures may re- 


\section{J. Bakhsheshian et al.}

spond differently to conservative treatment. Although the current level of evidence is low (Level IV), this warrants further investigation because it could impact the results of grouped thoracolumbar cohorts.,36 Anatomically, the thoracic spine differs from the thoracolumbar junction, which differs from the mid and lower lumbar spine. Lower lumbar burst fractures are rare and are commonly included in the thoracolumbar studies. ${ }^{10,14}$ Interestingly, 9 lowlevel studies $(20 \%)$ were included in the present review that investigated the conservative management of lumbar burst fractures separately from thoracolumbar burst fractures. The functional outcomes of treating lumbar burst fractures conservatively were relatively higher than those reported by grouped thoracolumbar fractures. ${ }^{7,10,11,14,35,43,52}$

This review is not without limitations. While several relevant high-level studies have been published, the majority include a heterogeneous population of burst fractures due to differences in age, level, and number of fractures, neurological status, and diagnostic imaging modalities used for the classification of the type of fracture. However, this may reflect the diversity of burst fractures that is clinically encountered and managed. Summarizing the discrepancies in the population of burst fractures and in clinical outcomes may help decrease the heterogeneity of future clinical studies. Extrapolation of the data to long-term consequences may be limited, because there are no high-level studies reporting on clinical outcome greater than 5 years. Another limitation is the use of the PubMed database (MEDLINE) as our only database in constructing this review; the inclusion of other databases may have yielded more thoracolumbar burst fracture studies. However, the MEDLINE database has been reliably and consistently used as the sole source of studies in systematic reviews, and is well accepted as a comprehensive source of relevant literature. ${ }^{27}$ Strengths of the current study include the highly systematic nature of the review in accordance with the Cochrane Collaboration Handbook on systematic reviews (http://handbook. cochrane.org). Furthermore, all studies related to traumatic thoracolumbar burst fractures within the MEDLINE database were located, consisting of a total of 447 studies in the last 20 years. Therefore, all the studies in which conservative management was used were obtained from this time period.

\section{Conclusions}

Based on the current systematic review, there are 9 high-level studies (Level I or II) that have investigated the conservative management of traumatic thoracolumbar burst fractures. In neurologically intact patients, there is no superior conservative management technique over another as supported by a high level of evidence. The appropriate method can be based on patient preference, comfort, and access to resources. There is a need for a high-level study comparing conservative techniques in neurologically compromised patients. A high level of evidence demonstrates similar functional outcome with conservative management when compared with open surgical operative management in patients who are neurologically intact. While the majority of the literature excluded pa- tients with neurological deficits, its presence may not be an absolute contraindication for conservative treatment as supported by a high level of evidence. More evidence is needed to further classify the appropriate burst fractures for conservative management to decrease variables that may impact the prognosis. This could help standardize future burst fracture characteristics, thereby allowing pooling of results in future meta-analyses to provide a higher level of evidence for conservative management.

\section{Disclosure}

The authors report no conflict of interest concerning the materials or methods used in this study or the findings specified in this paper.

Author contributions to the study and manuscript preparation include the following. Conception and design: Smith, Bakhsheshian, Dahdaleh, Scheer. Acquisition of data: Bakhsheshian, Fakurnejad, Scheer. Analysis and interpretation of data: Bakhsheshian, Scheer. Drafting the article: Smith, Bakhsheshian, Scheer. Critically revising the article: all authors. Reviewed submitted version of manuscript: all authors. Approved the final version of the manuscript on behalf of all authors: Smith. Administrative/technical/material support: Bakhsheshian, Fakurnejad, Scheer. Study supervision: Smith.

\section{References}

1. Abudou M, Chen X, Kong X, Wu T: Surgical versus non-surgical treatment for thoracolumbar burst fractures without neurological deficit. Cochrane Database Syst Rev 6:CD005079, 2013

2. Ağuş H, Kayali C, Arslantaş M: Nonoperative treatment of burst-type thoracolumbar vertebra fractures: clinical and radiological results of 29 patients. Eur Spine J 14:536-540, 2005

3. Al-Khalifa FK, Adjei N, Yee AJ, Finkelstein JA: Patterns of collapse in thoracolumbar burst fractures. J Spinal Disord Tech 18:410-412, 2005

4. Alanay A, Yazici M, Acaroglu E, Turhan E, Cila A, Surat A: Course of nonsurgical management of burst fractures with intact posterior ligamentous complex: an MRI study. Spine (Phila Pa 1976) 29:2425-2431, 2004

5. Aligizakis A, Katonis P, Stergiopoulos K, Galanakis I, Karabekios S, Hadjipavlou A: Functional outcome of burst fractures of the thoracolumbar spine managed non-operatively, with early ambulation, evaluated using the load sharing classification. Acta Orthop Belg 68:279-287, 2002

6. Alpantaki K, Bano A, Pasku D, Mavrogenis AF, Papagelopoulos PJ, Sapkas GS, et al: Thoracolumbar burst fractures: a systematic review of management. Orthopedics 33:422-429, 2010

7. An HS, Simpson JM, Ebraheim NA, Jackson WT, Moore J, O'Malley NP: Low lumbar burst fractures: comparison between conservative and surgical treatments. Orthopedics 15: 367-373, 1992

8. Andreychik DA, Alander DH, Senica KM, Stauffer ES: Burst fractures of the second through fifth lumbar vertebrae. Clinical and radiographic results. J Bone Joint Surg Am 78:11561166, 1996

9. Bailey CS, Urquhart JC, Dvorak MF, Nadeau M, Boyd MC, Thomas KC, et al: Orthosis versus no orthosis for the treatment of thoracolumbar burst fractures without neurologic injury: a multicenter prospective randomized equivalence trial. Spine J [epub ahead of print], 2013

10. Blanco JF, De Pedro JA, Hernández PJ, Paniagua JC, Framiñán A: Conservative management of burst fractures of the fifth lumbar vertebra. J Spinal Disord Tech 18:229-231, 2005

11. Butler JS, Fitzpatrick P, Ni Mhaolain AM, Synnott K, O'Byrne JM: The management and functional outcome of isolated burst 


\section{Evidence-based conservative management of burst fractures}

fractures of the fifth lumbar vertebra. Spine (Phila Pa 1976) 32:443-447, 2007

12. Butler JS, Walsh A, O'Byrne J: Functional outcome of burst fractures of the first lumbar vertebra managed surgically and conservatively. Int Orthop 29:51-54, 2005

13. Cantor JB, Lebwohl NH, Garvey T, Eismont FJ: Nonoperative management of stable thoracolumbar burst fractures with early ambulation and bracing. Spine (Phila Pa 1976) 18:971976, 1993

14. Chan DP, Seng NK, Kaan KT: Nonoperative treatment in burst fractures of the lumbar spine (L2-L5) without neurologic deficits. Spine (Phila Pa 1976) 18:320-325, 1993

15. Chow GH, Nelson BJ, Gebhard JS, Brugman JL, Brown CW, Donaldson DH: Functional outcome of thoracolumbar burst fractures managed with hyperextension casting or bracing and early mobilization. Spine (Phila Pa 1976) 21:2170-2175, 1996

16. Dai LY, Jiang LS, Jiang SD: Conservative treatment of thoracolumbar burst fractures: a long-term follow-up results with special reference to the load sharing classification. Spine (Phila Pa 1976) 33:2536-2544, 2008

17. Dai LY, Jiang SD, Wang XY, Jiang LS: A review of the management of thoracolumbar burst fractures. Surg Neurol 67: 221-231, 2007

18. de Klerk LW, Fontijne WP, Stijnen T, Braakman R, Tanghe $\mathrm{HL}$, van Linge B: Spontaneous remodeling of the spinal canal after conservative management of thoracolumbar burst fractures. Spine (Phila Pa 1976) 23:1057-1060, 1998

19. Dendrinos GK, Halikias JG, Krallis PN, Asimakopoulos A: Factors influencing neurological recovery in burst thoracolumbar fractures. Acta Orthop Belg 61:226-234, 1995

20. Denis F: The three column spine and its significance in the classification of acute thoracolumbar spinal injuries. Spine (Phila Pa 1976) 8:817-831, 1983

21. Denis F, Armstrong GW, Searls K, Matta L: Acute thoracolumbar burst fractures in the absence of neurologic deficit. A comparison between operative and nonoperative treatment. Clin Orthop Relat Res (189):142-149, 1984

22. Finn CA, Stauffer ES: Burst fracture of the fifth lumbar vertebra. J Bone Joint Surg Am 74:398-403, 1992

23. Gertzbein SD: Scoliosis Research Society. Multicenter spine fracture study. Spine (Phila Pa 1976) 17:528-540, 1992

24. Gnanenthiran SR, Adie S, Harris IA: Nonoperative versus operative treatment for thoracolumbar burst fractures without neurologic deficit: a meta-analysis. Clin Orthop Relat Res 470:567-577, 2012

25. Ha KI, Han SH, Chung M, Yang BK, Youn GH: A clinical study of the natural remodeling of burst fractures of the lumbar spine. Clin Orthop Relat Res (323):210-214, 1996

26. Hartman MB, Chrin AM, Rechtine GR: Non-operative treatment of thoracolumbar fractures. Paraplegia 33:73-76, 1995

27. Haynes RB, McKibbon KA, Wilczynski NL, Walter SD, Werre SR: Optimal search strategies for retrieving scientifically strong studies of treatment from Medline: analytical survey. BMJ 330:1179, 2005

28. Hitchon PW, Torner JC, Haddad SF, Follett KA: Management options in thoracolumbar burst fractures. Surg Neurol 49:619-627, 1998

29. Howick J, Chalmers I, Glasziou P, Greenhalgh T, Heneghan C, Liberati A, et al: The 2011 Oxford CEBM Levels of Evidence (Introductory Document). Oxford: Centre of Evidence Based Medicine, 2011 (http://www.cebm.net/mod_product/ design/files/CEBM-Levels-of-Evidence-Introduction-2.1.pdf) [Accessed May 14, 2014]

30. Howick J, Chalmers I, Glasziou P, Greenhalgh T, Heneghan C, Liberati A, et al: Explanation of the 2011 Oxford Centre for Evidence-Based Medicine (OCEBM) Levels of Evidence (Background Document). Oxford: Centre for Evidence Based Medicine, 2011 (http://www.cebm.net/mod_product/ design/files/CEBM-Levels-of-Evidence-Background-Docu ment-2.1.pdf) [Accessed May 14, 2014]
31. Howick J, Chalmers I, Glasziou P, Greenhalgh T, Heneghan C, Liberati A, et al: The Oxford Levels of Evidence 2. Oxford: Centre For Evidence Based Medicine, 2011 (http:// www.cebm.net/mod_product/design/files/CEBM-Levels-ofEvidence-2.1.pdf) [Accessed May 15, 2014]

32. Hu R, Mustard CA, Burns C: Epidemiology of incident spinal fracture in a complete population. Spine (Phila Pa 1976) 21:492-499, 1996

33. Joaquim AF, Daubs MD, Lawrence BD, Brodke DS, Cendes $\mathrm{F}$, Tedeschi $\mathrm{H}$, et al: Retrospective evaluation of the validity of the Thoracolumbar Injury Classification System in 458 consecutively treated patients. Spine J 13:1760-1765, 2013

34. Kinoshita H, Nagata Y, Ueda H, Kishi K: Conservative treatment of burst fractures of the thoracolumbar and lumbar spine. Paraplegia 31:58-67, 1993

35. Knight RQ, Stornelli DP, Chan DP, Devanny JR, Jackson KV: Comparison of operative versus nonoperative treatment of lumbar burst fractures. Clin Orthop Relat Res (293):112-121, 1993

36. Koller H, Acosta F, Hempfing A, Rohrmüller D, Tauber M, Lederer S, et al: Long-term investigation of nonsurgical treatment for thoracolumbar and lumbar burst fractures: an outcome analysis in sight of spinopelvic balance. Eur Spine J 17:1073-1095, 2008

37. Kraemer WJ, Schemitsch EH, Lever J, McBroom RJ, McKee MD, Waddell JP: Functional outcome of thoracolumbar burst fractures without neurological deficit. J Orthop Trauma 10: 541-544, 1996

38. Lee HM, Kim HS, Kim DJ, Suk KS, Park JO, Kim NH: Reliability of magnetic resonance imaging in detecting posterior ligament complex injury in thoracolumbar spinal fractures. Spine (Phila Pa 1976) 25:2079-2084, 2000

39. Lee JY, Vaccaro AR, Schweitzer KM Jr, Lim MR, Baron EM, Rampersaud R, et al: Assessment of injury to the thoracolumbar posterior ligamentous complex in the setting of normalappearing plain radiography. Spine J 7:422-427, 2007

40. Levels of Evidence for Primary Research Question. Clin Orthop Relat Res, 2013 (http://www.springer.com/cda/content/ document/cda_downloaddocument/Levels+of+Evidence. pdf?SGWID=0-0-45-957938-p173705903) [Accessed May 15, 2014]

41. Magerl F, Aebi M, Gertzbein SD, Harms J, Nazarian S: A comprehensive classification of thoracic and lumbar injuries. Eur Spine J 3:184-201, 1994

42. Mehta JS, Reed MR, McVie JL, Sanderson PL: Weight-bearing radiographs in thoracolumbar fractures: do they influence management? Spine (Phila Pa 1976) 29:564-567, 2004

43. Mick CA, Carl A, Sachs B, Hresko MT, Pfeifer BA: Burst fractures of the fifth lumbar vertebra. Spine (Phila Pa 1976) 18: $1878-1884,1993$

44. Mohanty SP, Venkatram N: Does neurological recovery in thoracolumbar and lumbar burst fractures depend on the extent of canal compromise? Spinal Cord 40:295-299, 2002

45. Moller A, Hasserius R, Redlund-Johnell I, Ohlin A, Karlsson MK: Nonoperatively treated burst fractures of the thoracic and lumbar spine in adults: a 23- to 41-year follow-up. Spine J 7:701-707, 2007

46. Mumford J, Weinstein JN, Spratt KF, Goel VK: Thoracolumbar burst fractures. The clinical efficacy and outcome of nonoperative management. Spine (Phila Pa 1976) 18:955-970, 1993

47. Öztürk I, Ertürer E, Sönmez MM, Sarı S, Şeker A, Seçkin MF: Early mobilization with customized TLSO brace in thoracolumbar burst fractures. Acta Orthop Traumatol Turc 46:373-378, 2012

48. Patwardhan AG, Li SP, Gavin T, Lorenz M, Meade KP, Zindrick M: Orthotic stabilization of thoracolumbar injuries. A biomechanical analysis of the Jewett hyperextension orthosis. Spine (Phila Pa 1976) 15:654-661, 1990

49. Post RB, van der Sluis CK, Leferink VJ, ten Duis HJ: Long- 


\section{J. Bakhsheshian et al.}

term functional outcome after type A3 spinal fractures: operative versus non-operative treatment. Acta Orthop Belg 75: 389-395, 2009

50. Rajasekaran S: Thoracolumbar burst fractures without neurological deficit: the role for conservative treatment. Eur Spine J 19 (Suppl 1):S40-S47, 2010

51. Schweitzer KM, Vaccaro AR, Harrop JS, Hurlbert J, Carrino JA, Rechtine GR, et al: Interrater reliability of identifying indicators of posterior ligamentous complex disruption when plain films are indeterminate in thoracolumbar injuries. J Orthop Sci 12:437-442, 2007

52. Seybold EA, Sweeney CA, Fredrickson BE, Warhold LG, Bernini PM: Functional outcome of low lumbar burst fractures. A multicenter review of operative and nonoperative treatment of L3-L5. Spine (Phila Pa 1976) 24:2154-2161, 1999

53. Shen WJ, Liu TJ, Shen YS: Nonoperative treatment versus posterior fixation for thoracolumbar junction burst fractures without neurologic deficit. Spine (Phila Pa 1976) 26:10381045,2001

54. Shen WJ, Shen YS: Nonsurgical treatment of three-column thoracolumbar junction burst fractures without neurologic deficit. Spine (Phila Pa 1976) 24:412-415, 1999

55. Siebenga J, Leferink VJ, Segers MJ, Elzinga MJ, Bakker FC, Haarman HJ, et al: Treatment of traumatic thoracolumbar spine fractures: a multicenter prospective randomized study of operative versus nonsurgical treatment. Spine (Phila Pa 1976) 31:2881-2890, 2006

56. Stadhouder A, Buskens E, Vergroesen DA, Fidler MW, de Nies F, Oner FC: Nonoperative treatment of thoracic and lumbar spine fractures: a prospective randomized study of different treatment options. J Orthop Trauma 23:588-594, 2009

57. Tezer M, Erturer RE, Ozturk C, Ozturk I, Kuzgun U: Conservative treatment of fractures of the thoracolumbar spine. Int Orthop 29:78-82, 2005

58. Thomas KC, Bailey CS, Dvorak MF, Kwon B, Fisher C: Comparison of operative and nonoperative treatment for thoracolumbar burst fractures in patients without neurological deficit: a systematic review. J Neurosurg Spine 4:351-358, 2006

59. Tropiano P, Huang RC, Louis CA, Poitout DG, Louis RP:
Functional and radiographic outcome of thoracolumbar and lumbar burst fractures managed by closed orthopaedic reduction and casting. Spine (Phila Pa 1976) 28:2459-2465, 2003

60. Vaccaro AR, Lehman RA Jr, Hurlbert RJ, Anderson PA, Harris M, Hedlund R, et al: A new classification of thoracolumbar injuries: the importance of injury morphology, the integrity of the posterior ligamentous complex, and neurologic status. Spine (Phila Pa 1976) 30:2325-2333, 2005

61. Weninger P, Schultz A, Hertz H: Conservative management of thoracolumbar and lumbar spine compression and burst fractures: functional and radiographic outcomes in 136 cases treated by closed reduction and casting. Arch Orthop Trauma Surg 129:207-219, 2009

62. White AA III, Panjabi MM, Posner I, Edwards WT, Hayes WC: Spinal stability: evaluation and treatment. Instr Course Lect 30:457-483, 1981

63. Wood K, Buttermann G, Mehbod A, Garvey T, Jhanjee R, Sechriest V: Operative compared with nonoperative treatment of a thoracolumbar burst fracture without neurological deficit. A prospective, randomized study. J Bone Joint Surg Am 85-A:773-781, 2003 (Erratum in J Bone Joint Surg Am 86A:1283, 2004)

64. Yazici M, Atilla B, Tepe S, Calisir A: Spinal canal remodeling in burst fractures of the thoracolumbar spine: a computerized tomographic comparison between operative and nonoperative treatment. J Spinal Disord 9:409-413, 1996

65. Yi L, Jingping B, Gele J, Baoleri X, Taixiang W: Operative versus non-operative treatment for thoracolumbar burst fractures without neurological deficit. Cochrane Database Syst $\operatorname{Rev}(4): C D 005079,2006$

Manuscript submitted January 25, 2014.

Accepted April 17, 2014.

Please include this information when citing this paper: DOI: 10.3171/2014.4.FOCUS14159.

Address correspondence to: Zachary A. Smith, M.D., Department of Neurological Surgery, Northwestern University, 676 N. St. Clair St., Ste. 2210, Chicago, IL 60611. email: zsmith@nmff.org. 